\title{
Colorectal Cancers, Screening in the General Population: Focusing
}

\author{
Type of article: Review \\ Boumediene Elhabachi; Mama Sidelmrabet Ben Brahim \\ Faculty of medicine University of Sidi Bel Abbes, Algeria \\ CHU Dr Hassani A.E.K, Algeria
}

\begin{abstract}
Colorectal cancers are common throughout the world, although their incidence varies across continents and countries. $28 \%$ of these cancers are rectal and two-thirds of the remaining $72 \%$ are of left colonic location. Screening and prevention have proven effective in reducing the incidence of these cancers and their mortality. The best screening results in the so-called average-risk general population have been obtained in the USA, where first-line endoscopy is the gold standard when in other countries, especially European ones; screening was done by the search for occult blood in the stool. This group, however, became heterogeneous due to the intervention of environmental factors and co-morbidities; a colonoscopy is then proposed to those subjects considered at average risk. Virtual colonoscopy has excellent sensitivity and specificity for one centimeter polyps. The serrated polyps, pre-cancerous lesions predominating on the right, are more difficult to detect.

Keywords: colorectal cancers; screening; average risk; virtual colonoscopy.
\end{abstract}

Corresponding author: Boumediene Elhabachi

Received: 23 February, 2019, Accepted: 29 Mars, 2019, English editing:29 Mars, 2019, Published: 1 Avril, 2019.

Screened by iThenticate..(02017-2019 KNOWLEDGE KINGDOM PUBLISHING.

\section{Introduction}

Colorectal cancer (CRC) is one of the most common cancers worldwide with 1 million new cases a year [1]. From the epidemiological point of view, the right colon extends to the splenic fissure, as well as to the left colic angle (without including it) and the left colon extends from the left colic angle to the-sigmoid hinge [2]. Seventy-two percent of these cancers are colonic, of which two thirds are in the left colon, and $28 \%$ are rectal. The localization of the lesions is of great importance in terms of diagnosis, surveillance, pathophysiology and obviously therapeutic.

Colorectal cancers are sporadic in 75 to $80 \%$ of cases [3]. This is essentially the average risk group aged 50 to 75 years. Subjects at average risk are exposed differently to environmental hazards and co-morbidities. Several scores have been proposed to evaluate the risk in this population including the Kaminski score. A colonoscopy is proposed to them as for the high risk group. "True" average risk subjects are screened for a trade-off between benefit and risk of the available means. The cost of CRC is getting more and more expensive and this trend is confirmed for years to come [4]. This cancer threatens the man in his life and society in its economy, hence the interest of the issue. 


\section{Epidemiology}

With more than one million cases diagnosed and 500,000 deaths [1] per year worldwide, this cancer is a public health problem [5]. Colorectal cancer (CRC) is the fourth leading cause of death in men and the third one in women worldwide. Its incidence increases with age [6]. The average age at diagnosis in men (60-65 years) is slightly earlier than in women (65-70 years). In men, the peak of mortality is between 65 and 70 years old and in the women between 70 and 75 years old. CRC are more common in. industrialized countries than in developing ones [5].

The CRC is the third most common cancer in the US and the third leading cause of cancer death $[8,9]$, while its incidence has declined significantly over the last four decades [8]. This decrease in incidence is due to screening programs but also to the trend towards healthier lifestyles [10]. In 2018, newly diagnosed cases were estimated to be at 140,250 , say $8.1 \%$ of all new cancer cases, and a death rate of 50,630 , or $8.3 \%$ of all cancer deaths [11-13 ]. Between 2004 and 2008, the incidence in men was 55 per 100,000 with a mortality of 20.7 per 100,000 and 41 per 100,000 among women with a mortality of 14.5 per 100,000, while emphasizing that the incidence was higher for African-Americans [9] .The 5-year survival during the period 2001-2007 averaged $65.5 \%$ for men (55\% for African-Americans) and $64.5 \%$ for women (56.9\% for Afro-Americans) [14].

\section{The Justification for screening}

Screening involves detecting colorectal cancer at an early stage at which the cancer is potentially curable.

Prevention aims to diagnose and remove precancerous lesions to reduce the incidence of colorectal cancer.

The term "screening" is often used to define the actual screening but also, by excess of language, prevention.

For justifying screening:

A sufficiently sensitive, specific and non-invasive screening tool is needed.

It must concern a sufficiently frequent and serious pathology.

It is necessary to have an effective therapeutic means of the detected lesions.

The CRCs meet all these criteria [15]. They are frequent and their screening has made it possible to reduce morbidity and mortality by CRC. Early cancers have a good prognosis with $89.9 \%$ survival at 5 years for stage I, whereas this rate drops to $71.1 \%$ in the case of lymph node involvement [11].

Unfortunately $21 \%$ of patients with CRC present a metastasis at diagnosis and about $50 \%$ will eventually metastasize, that is what explains the high rate of mortality in these conditions [11,16] and justifies prevention, mass screening and the organization of public awareness campaigns for greater adherence to screening programs [17]. 


\section{Precancerous lesions}

\section{The adenomatous polyp}

It is a benign epithelial tumor, prevalent in the general population [18] and more common in men than in women. According to the data of the autopsies, one- third of the population presents an adenomatous polyp [2, 19]. The term polyp is unsuitable for an adenoma because a polyp may not be adenomatous. An only pathological examination can determine the type of polypoid lesion.

Up to $80 \%$ of colorectal cancers result from the malignant transformation of an adenomatous polyp with a first step in the genesis of the adenoma followed by its growth and then its malignant degeneration [20].

Among 1000 adenomas, only 100 will reach the size of $1 \mathrm{~cm}$ and 37 will increase in size [2]; an invasive carcinoma is found in $9.3 \%$ after a follow-up of 108 months and the cumulative risk of malignancy is $2.5 \%$ at 5 years, $8 \%$ at 10 years and $24 \%$ to 20 years [21].

The size is a major risk factor for malignant transformation. This risk is $0.3 \%$ for an adenoma less than $1 \mathrm{~cm}, 9 \%$ for an adenoma of size between 1 and $2 \mathrm{~cm}$ and $28 \%$ for adenomas greater than $2 \mathrm{~cm} \mathrm{[2].}$

In addition to size, which is an important element of transformation, we must consider the histological types (presence of villous component) and the presence of severe dysplasia [18, 22].

It is estimated that ten years is the time required for an adenomatous polyp to degenerate, that is why 10 years are the time interval for screening after a first normal colonoscopy [23].

\section{Serrated polyps [24-28]}

According to the World Health Organization WHO classification [27,29] it is a heterogeneous group consisting of three different entities with different malignant evolution potential:

\section{- Hyperplastic polyps}

They are very common, representing $75 \%$ of serrated polyps. These polyps have no potential for degeneration.

\section{- Sessile Serrated Adenoma}

It represents 15 to $20 \%$ of serrated polyps with $90 \%$ in the right colon. It occurs in $09 \%$ of people who have been colonoscopically examined and are more frequent in women. The risk of transformation is lower than that of a conventional adenoma but the transformation is faster in the case of occurrence of dysplasia or a size greater than $1 \mathrm{~cm}$. In this case the existence of a synchronous degeneration is important and explains why the interval of surveillance between 2 endoscopies is different for the two types of polyps, namely classic or adenomatous and serrated.

- The traditional serrated adenoma

It is rare, with a potential for degeneration.

\section{Environmental risk factors and co-morbidities}

These are the lifestyle factors. They are modifiable and increase the risk of cancer, mainly for the average risk group. 


\begin{abstract}
-Alcohol consumption
It increases the risk of colorectal cancer without any difference between the colonic or rectal locations and this risk increases according to the quantity ingested and the duration of consumption, the risk increases by $15 \%$ for a consumption increase of 100 gr per week [30].

\section{- Smoking}

It is a risk factor for adenomas and colorectal cancers. Compared with nonsmokers, smokers and former smokers have a significantly higher risk of colorectal cancer and death, although the risk for rectal cancer is greater and evident [31,32].
\end{abstract}

\title{
- Obesity and overweight
}

The increase in Body Mass Index is associated with an increased risk of colon cancer in both sexes, but this increase is more pronounced for men, whereas BMI is a risk factor for the development of rectal cancer, but only in men, which means that obesity is a risk factor for CRC that depends on sex and the site [33].

\section{- The consumption of meat and sausages}

Red meats [34] (beef, mutton, pork, lamb, goat, and veal) and deli meats (meat preserved by smoking, drying, salting or adding preservatives) are criminalized. The risk is increased by $29 \%$ for a 100 gr portion of red meat per day and $21 \%$ for a 50 gr portion of deli meats per day [35-37].

\section{Average risk group}

Everyone is at average risk from the age of 50[38-40]. Age increases, by itself, the risk of colorectal cancer [41]. The risk of a population of 50 to 75 years of developing colorectal cancer without any other risk factor is estimated between 3.5 [2] and $4.5 \%$ [6].

People at average risk eligible for screening:

- Men and women between 50 and 74 years old.

- Asymptomatic people at risk Medium:

- No family history of CCR.

- No personal history of adenoma, serrated polyp or CCR.

- No personal history of chronic inflammatory diseases of intestine.

- Absence of colonoscopy within 5 years.

- No search for occult blood in stools dating from less than 2 years.

- Absence of serious damage to the general condition by another cancer for example making this test useless.

\section{Ineligible persons}

- Negative complete colonoscopy within 5 years or Hemoccult test in the previous 12 months.

- Symptomatology requiring exploration by colonoscopy: rectorrhagia, melaena, recent unexplained abdominal pain especially after 50 years old and transitory disorders of recent occurrence in the form of unusual diarrhea or constipation.

- Increased and very high- risk levels requiring specific monitoring. 


\section{Means of screening}

1) Screening by stool tests "Stool-Based Tests"

They consist of looking for occult blood in the stool by guaiac test (gFOBT of Fecal Occult Blood Test), or by immunological test (Fecal immunochemical tests (FITs or iFOBT) and in the search for alterations of the abnormal exfoliated DNA (search for the APC gene mutation). These tests are not invasive and require no preparation.

2) Endoscopy: This can be a total colonoscopy or rectosigmoidoscopy.

3) Virtual colonoscopy.

\section{Screening strategies}

In the US where colonoscopy is the primary means of screening [38,42]. Four strategies are possible with the same survival gain and an equal benefit ratio risk $[39,40]:$

- Colonoscopy every 10 years.

- stool test: annual fecal occult blood test by guaiac test or immunehistochemical test (FIT) or by FIT coupled with the abnormal DNA test every three years.

- Sigmoidoscopy every 5 to 10 years with possibly the annual test (FIT).

- Virtual colonoscopy (CTC) every 5 years.

Some countries like France perform mass screening in two stages. The first is that of selection by the search for occult blood in the stool (currently the immunological test). In case of positive test and in a second time called "diagnosis" a colonoscopy is performed.

This approach is based on the argument that a first-intention colonoscopy will have a very high rate of negative colonoscopies, so that this examination no longer meets the criteria required for screening.

\section{Evolution of ideas}

However, this (French) vision could not ignore the fact that colonoscopy reduced, although more for the distal than proximal colon, mortality and the incidence of colorectal cancers [43-44]. Thus, a colonoscopy of Prevention could be carried out on an individual basis in an average-risk subject after informing him about the advantages and disadvantages of the examination and obtaining his informed consent [45].

In addition, the so-called average risk population is very heterogeneous because people in this group are exposed in a different way to environmental factors and comorbidities. Some of them are close to the high-risk group; they are identified by means of scores [46] and assigned to colonoscopy screening from the outset [45]. This evolution of ideas in France is close, at least for one category of subjects, to the American attitude that proposes, from the start, endoscopy as a means of screening and prevention. 


\section{Discussion}

The incidence, morbidity and mortality of CRCs justify their prevention and mass screening. For this purpose, colonoscopy is the gold standard. If colonoscopy was performed as a first-line treatment for the entire population over the age of 50, the high rate of negative examinations would no longer allow endoscopy to meet the required criteria for screening. The severity of this disease, the performance of colonoscopy on the left colon and the higher frequency of CRCs on the left (2/3 of colon cancers) allowed the emergence of rectosigmoidoscopy as a good alternative. Indeed, adenomatous polyps are the most common precancerous lesion on the left and the detection rate depends on the expertise of the endoscopist. In the right colon serrated polyps are the most common precancerous lesion. These serrated polyps including sessile serrated adenomas are difficult to locate and an endoscopist with a high rate detection of adenomatous polyps does not necessarily have the same expertise for serrated polyps. Virtual colonoscopy also faces a difficulty of detection of these polyps. In the USA screening strategies have multiplied to overcome the invasive nature of colonoscopy. All strategies take into account epidemiological and pathological data.

In France, as in other countries, stool testing is not enough for some people who theoretically belong to the average risk group. Environmental factors and / or comorbidities rank them in the high-risk group. These people, outclassed, will benefit from individual screening. Regardless of these environmental factors and comorbidities, it is possible to propose a colonoscopy in an average-risk person after obtaining informed consent.

\section{Conclusion}

The effectiveness of CRC screening in the average-risk group is clear. Screening with fecal occult blood testing has proven effectiveness; this one is, however, inferior to that of endoscopy. This risk group is no longer considered a homogeneous group and among this group, some subjects are considered high risk and they are entrusted with endoscopic screening. In middle-risk people, we can say "true average-risk group" screening must find a tradeoff between benefit and risk. The VC can be used as a non-invasive means. It is sensitive and specific for polyps greater than $1 \mathrm{~cm}$ that have a risk of degeneration. In case of particularly multiple lesions and size larger than $1 \mathrm{~cm}$, a colonoscopy must be performed and the right colon is de facto explored. Regarding right colon lesions where serrated polyps are more common, the VC is not very sensitive. This difficulty of detection being also posed to the colonoscopy, it would perhaps be justified to propose a search for abnormal DNA or a Fecal immunochemical tests (FITs) in the saddle in case of negative $\mathrm{VC}$ in order to limit the number of lesions missed on the right and thus to decrease the interval cancers. 


\section{Conflict of interest statement}

We certify that there is no conflict of interest with any financial organization in the subject matter or materials discussed in this manuscript.

\section{Authors' biography}

No Biography

\section{References}

[1] Corrêa., R.d.S., et al., Rectal cancer survival in a Brazilian Cancer Reference Unit. JCOL, 2016. 36(4): p. 203-207. https://doi.org/10.1016/j.jcol.2016.04.015

[2] [Consensus conference: Prevention Screening and Management of the Colonic Cancers. Paris, France, January 29-30, 1998. Proceedings]. Gastroenterol Clin Biol, 1998. 22(3 Suppl): p. S1-295.

[3] Markowitz, S.D. and M.M. Bertagnolli, Molecular origins of cancer: Molecular basis of colorectal cancer. N Engl J Med, 2009. 361(25): p. 244960. $\quad$ https://doi.org/10.1056/NEJMra0804588 PMid:20018966 PMCid:PMC2843693

[4] Orangio, G.R., The Economics of Colon Cancer. Surg Oncol Clin N Am, 2018. 27(2): p. 327-347. https://doi.org/10.1016/j.soc.2017.11.007PMid:29496093

[5] Organization., W.H., International Agency for Research on Cancer (IARC). Available at: http://www-dep.iarc.fr/ AccessedDecember 3, 2011, 2011

[6] Moore, J.S. and T.H. Aulet, Colorectal Cancer Screening. Surg Clin North Am, $2017 . \quad 97(3)$ : p. 487-502. https://doi.org/10.1016/j.suc.2017.01.001PMid:28501242

[7] SEER stat fact sheets: colon and rectum cancer. Available at: http://seer.cancer gov/statfacts/html/colorect.html, Accessed September 16, 2016.

[8] Siegel, R.L., et al., Colorectal cancer statistics, 2017. CA Cancer J Clin, 2017. 67(3): p. 177-193. https://doi.org/10.3322/caac.21395PMid:28248415

[9] Siegel, R.L., K.D. Miller, and A. Jemal, Cancer statistics, 2015. CA Cancer J Clin, 2015. 65(1): p. 5-29. https://doi.org/10.3322/caac.21254PMid:25559415

[10] Hall, N.C. and A.T. Ruutiainen, Colorectal Cancer:: Imaging Conundrums. Surg Oncol Clin N Am, 2018. 27(2): p. 289-302. https://doi.org/10.1016/j.soc.2017.11.004PMid:29496090

[11] Cancer Stat Facts: Colorectal Cancer. https://seer.cancer.gov/statfacts/html/colorect.html, 2018.

[12] Bailey, C.E., et al., Increasing disparities in the age-related incidences of colon and rectal cancers in the United States, 1975-2010. JAMA Surg, $2015 . \quad 150(1)$ : 2 p. 22.https://doi.org/10.1001/jamasurg.2014.1756 PMid:25372703 PMCid:PMC4666003 
[13] Murphy, G., et al., Sex disparities in colorectal cancer incidence by anatomic subsite, race and age. Int J Cancer, 2011. 128(7): p. 166875. https://doi.org/10.1002/ijc.25481 PMid:20503269 PMCid:PMC3031675

[14] National Cancer Institute.Rectal Cancer Treatment. http://www.cancer.gov/, 2011.

[15] Pox, C.P., Controversies in colorectal cancer screening. Digestion, 2014. 89(4): p. 274-81. https://doi.org/10.1159/000363287 PMid:25034478

[16] Van Cutsem, E., et al., Metastatic colorectal cancer: ESMO Clinical Practice Guidelines for diagnosis, treatment and follow-up. Ann Oncol, $2014 . \quad 25 \quad$ Suppl $\quad 3: \quad$ p. $\quad$ iii1-9. https://doi.org/10.1093/annonc/mdu260

[17] Yeazel, M.W., et al., Colorectal cancer screening adherence in a general population. Cancer Epidemiol Biomarkers Prev, 2004. 13(4): p. 6547.

[18] Eide, T.J., Natural history of adenomas. World J Surg, 1991. 15(1): p. 36.https://doi.org/10.1007/BF01658952 PMid:1994603

[19] Rex, D.K., et al., Quality in the technical performance of colonoscopy and the continuous quality improvement process for colonoscopy: recommendations of the U.S. Multi-Society Task Force on Colorectal Cancer. Am J Gastroenterol, 2002. 97(6): p. 1296-308. https://doi.org/10.1111/j.1572-0241.2002.05812.xPMid:12094842

[20] Takayama, T., et al., Aberrant crypt foci of the colon as precursors of adenoma and cancer. N Engl J Med, 1998. 339(18): p. 1277-84. https://doi.org/10.1056/NEJM199810293391803PMid:9791143

[21] Pidala, M.J. and M.V. Cusick, The Difficult Colorectal Polyp. Surg Clin North Am, 2017. 97(3): p. 515-527. https://doi.org/10.1016/j.suc.2017.01.003PMid:28501244

[22] Eide, T.J., Risk of colorectal cancer in adenoma-bearing individuals within a defined population. Int $\mathbf{J}$ Cancer, 1986. 38(2): p. 173-6. https://doi.org/10.1002/ijc.2910380205 PMid:3733258

[23] Singh, H., et al., Risk of developing colorectal cancer following a negative colonoscopy examination: evidence for a 10 -year interval between colonoscopies. JAMA, 2006. 295(20): p. 2366-73. https://doi.org/10.1001/jama.295.20.2366PMid:16720822

[24] Bateman, A.C., Pathology of serrated colorectal lesions. J Clin Pathol, 2014. 67(10): p. 865-74. https://doi.org/10.1136/jclinpath-2014202175PMid:24561317

[25] Hetzel, J.T., et al., Variation in the detection of serrated polyps in an average risk colorectal cancer screening cohort. Am J Gastroenterol, $2010 . \quad 105(12)$ : $2656-64$. https://doi.org/10.1038/ajg.2010.315PMid:20717107

[26] Leggett, B. and V. Whitehall, Role of the serrated pathway in colorectal cancer pathogenesis. Gastroenterology, 2010. 138(6): p. 2088-100. https://doi.org/10.1053/j.gastro.2009.12.066PMid:20420948

[27] Saito, S., H. Tajiri, and M. Ikegami, Serrated polyps of the colon and rectum: Endoscopic features including image enhanced endoscopy. World J Gastrointest Endosc, 2015. 7(9): p. 860-71. https://doi.org/10.4253/wjge.v7.i9.860 PMid:26240687 PMCid:PMC4515420

[28] Torlakovic, E. and D.C. Snover, Serrated adenomatous polyposis in humans. Gastroenterology, 1996. 110(3): p. 748-55. https://doi.org/10.1053/gast.1996.v110.pm8608884PMid:8608884 
[29] Longacre, T.A. and C.M. Fenoglio-Preiser, Mixed hyperplastic adenomatous polyps/serrated adenomas. A distinct form of colorectal neoplasia. Am J Surg Pathol, 1990. 14(6): p. 524-37. https://doi.org/10.1097/00000478-199006000-00003PMid:2186644

[30] Moskal, A., et al., Alcohol intake and colorectal cancer risk: a doseresponse meta-analysis of published cohort studies. Int J Cancer, 2007. 120(3): p. 664-71. https://doi.org/10.1002/ijc.22299PMid:17096321

[31] Liang, P.S., T.Y. Chen, and E. Giovannucci, Cigarette smoking and colorectal cancer incidence and mortality: systematic review and metaanalysis. Int J Cancer, 2009. 124(10): p. 2406-15. https://doi.org/10.1002/ijc.24191 PMid:19142968

[32] Paskett, E.D., et al., Associationbetween cigarette smoking and colorectal cancer in the Women's Health Initiative. J Natl Cancer Inst, $2007 . \quad$ 99(22): $1729-35$. https://doi.org/10.1093/jnci/djm176PMid:18000222

[33] Larsson, S.C. and A.Wolk, Obesity and colon and rectal cancer risk: a meta-analysis of prospective studies. Am J Clin Nutr, 2007. 86(3): p. 55665. https://doi.org/10.3945/ajcn.2009.27480PMid:17823417

[34] Pan, P., J.Yu, and L.S. Wang, Colon Cancer: What We Eat. Surg Oncol Clin N Am, 2018. 27(2): p. 243-267. https://doi.org/10.1016/j.soc.2017.11.002 PMid:29496088 PMCid:PMC5836483

[35] Giovannucci, E., et al., Intake of fat, meat, and fiber in relation to risk of colon cancer in men. Cancer Res, 1994. 54(9): p. 2390-7.

[36] Graham, S. and M. Swanson, Relation of meat, fat, and fiber intake to the risk of colon cancer in women. $\mathrm{N}$ Engl J Med, 1992. 326(3): p. 199-200; author 201-2. https://doi.org/10.1056/NEJM199201163260312

[37] Loosli, A.R., Relation of meat, fat, and fiber intake to the risk of colon cancer in women. N Engl J Med, 1992. 326(3): p. 200; author reply 201-2. https://doi.org/10.1056/NEJM199201163260312

[38] National Comprehensive Cancer Network. NCCN clinical practice guidelines in oncology (NCCN guidelines): colorectal cancer screening.2016.

[39] National Comprehensive Cancer Network. NCCN clinical practice guidelines in oncology (NCCN guidelines): colorectal cancer screening., 2018.

[40] Knudsen, A.B., et al., Estimation of Benefits, Burden, and Harms of Colorectal Cancer Screening Strategies: Modeling Study for the US Preventive Services Task Force. JAMA, 2016. 315(23): p. 2595-609. https://doi.org/10.1001/jama.2016.6828 $\quad$ PMid:27305518 PMCid:PMC5493310

[41] Bibbins-Domingo, K., et al., Screening for Colorectal Cancer: US Preventive Services Task Force Recommendation Statement. JAMA, 2016. 315(23): $\quad$ p. 2564-2575. https://doi.org/10.1001/jama.2016.5989 PMid:27304597

[42] Lin, J.S., et al., Screening for Colorectal Cancer: Updated Evidence Report and Systematic Review for the US Preventive Services Task Force. JAMA, $2016 . \quad 315(23): \quad$ p. 2576-94. https://doi.org/10.1001/jama.2016.3332PMid:27305422

[43] Brenner, H., C. Stock, and M. Hoffmeister, Effect of screening sigmoidoscopy and screening colonoscopy on colorectal cancer incidence 
and mortality: systematic review and meta-analysis of randomised controlled trials and observational studies. BMJ, 2014. 348: p. g2467. https://doi.org/10.1136/bmj.g2467

[44] Nishihara, R., et al., Long-term colorectal-cancer incidence and mortality after lower endoscopy. N Engl J Med, 2013. 369(12): p. 1095-105. https://doi.org/10.1056/NEJMoa1301969

PMid:24047059 PMCid:PMC3840160

[45] Heresbach, D., P. Pienkowski, and S. Chaussade, Prévention du Cancer Colo-rectal par Coloscopie, en dehors du dépistage en population :Consensus et position de la SFED. SFED, 2016. https://doi.org/10.1007/s10190-016-0534-5

[46] Kaminski, M.F., et al., A score to estimate the likelihood of detecting advanced colorectal neoplasia at colonoscopy. Gut, 2014. 63(7): p. 11129.https://doi.org/10.1136/gutjnl-2013-304965 PMCid:PMC4078748 